\title{
EFFECT OF SINTERING PROFILES ON THE PROPERTIES AND AGEING RESISTANCE OF Y-TZP CERAMIC
}

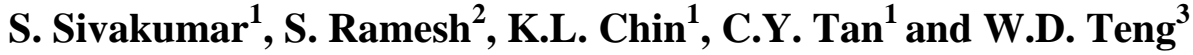 \\ ${ }^{1}$ Ceramics Technology Laboratory \\ University Tenaga Nasional, \\ 43009 Kajang, Selangor, Malaysia \\ ${ }^{2}$ Centre of Advanced Manufacturing \& Material Processing (AMMP), Department of \\ Engineering Design and Manufacture, Faculty of Engineering \\ University of Malaya \\ 50603 Kuala Lumpur, Malaysia \\ Email: ramesh79@um.edu.my \\ ${ }^{3}$ Ceramics Technology Group \\ SIRIM Berhad, 40911 Shah Alam, Selangor, Malaysia
}

\begin{abstract}
A commercially available Y-TZP ceramic powder was fabricated under four different sintering profiles in order to investigate the effects of conventional single-stage sintering (SSS) with dwell times of $1 \mathrm{~min}$ and $2 \mathrm{~h}$, respectively, compared with two-stage sintering (TSS), on the physical and mechanical properties of Y-TZP. Sintering was performed up to $1400^{\circ} \mathrm{C}$ at a ramp rate of $10^{\circ} \mathrm{C} / \mathrm{min}$. It was revealed that samples sintered via TSS yielded better properties than the SSS samples sintered at $1400^{\circ} \mathrm{C}$ using a dwell time of $2 \mathrm{~h}$. In the hydrothermal ageing test, TSS samples did not undergo low-temperature degradation via the tetragonal to monoclinic phase transformation. Nevertheless, it was found by XRD analysis that Y-TZP ceramics sintered by the SSS method using a short dwell time of 1 min were effective in maintaining tetragonal phase stability after $50 \mathrm{~h}$ of exposure to superheated steam conditions.
\end{abstract}

Keywords: Single-stage sintering, two-stage sintering, mechanical properties, Y-TZP

\section{INTRODUCTION}

Zirconia ceramics have gained much interest for industrial applications since the discovery of transformation toughening phenomena (Garvie et al., 1975). For instance, yttria-stabilised zirconia exhibits high values of fracture toughness, above $5 \mathrm{MPam}^{1 / 2}$ (Masaki, 1986; Tsukuma et al., 1984; Cottom and Mayo, 1996), thus making it a suitable candidate for a wide range of structural applications including cutting tools, valve guides, extrusion dies, abrasive tools, etc. (Ran et al., 2006). Over the last 10 years, research has been performed on nanocrystalline materials in order to investigate the enhancement of their mechanical, optical, magnetic and electronic properties (Bowen and Carry, 2002). Due to higher sintering stresses attributed to an increased surface area, the sinterability of nanoparticles is superior to that of fine particles; however, the accompanying extensive grain growth occurring during densification with the SSS method poses a serious disadvantage for the sintering of nanocrystalline particles. The processing of nano-structured powders to produce dense pieces while retaining a nanometric microstructure $(<100 \mathrm{~nm})$ by traditional forming techniques followed by presurreless sintering is difficult. Recently, nanocrystalline powders of high 
purity have been made available from various processes such as precipitation, sol-gel and hydrothermal methods (Bowen and Carry, 2002). In order to produce nanostructured ceramics, two commonly used techniques are spark plasma sintering and hot pressing (Wang and Gao, 2005; Weibel et al., 2007). These methods enable the use of rapid sintering rates to produce powders with high density and ultrafine grain structure. These processes, however, are not favourable for most industrial applications simply because of the high production cost, shape complexity and small product size (Basu et al., 2004; Dobedoe et al. 2003). It is a general fact that the increase in grain size during presureless sintering depends on the forming method and the firing temperature (Mazaheri et al., 2008). Nanocrystalline ceramics often have a high degree of agglomeration, which in turn causes the development of two types of pores, i.e. interagglomerate pores (micrometric) and intra-agglomerate pores (nanometric) within the agglomerate itself (Bowen and Carry, 2002). Inter-agglomerate pores may be eliminated through the application of high temperature; unfortunately, such an application also encourages an increase in the grain size.

Sintering is a process governed by capillary action which acts as a driving force resulting in atomic diffusion to cause the elimination of interparticle pores within a compact material (Coble and Cannon, 1978). The capillary forces of sintering are dependent on the surface area, while for growth these forces are dependent on the grain boundary; these two quantities do not vary much in magnitude. The final stage of growth can be reduced by studying the variations involved in the factors contributing to grain boundary diffusion and grain boundary migration, which in turn can be manipulated through various sintering profiles (Chen and Chen, 1997; Chen and Wang, 2000). Traditionally, sintering of zirconia ceramics has been done through one cycle of heating, holding and cooling, which may be referred to as single-stage sintering (SSS). Heating is performed to achieve temperatures in the range of $1500^{\circ} \mathrm{C}$ to $1550^{\circ} \mathrm{C}$ until the maximum density is reached, then the temperature is held for approximately $2 \mathrm{~h}$ and finally cooled to room temperature. It is during the heating stage that the grain size increases continuously. Under these conditions, even though sub-micron yttria stabilised powders are used, mechanical strength may be reduced. A new technique developed by Chen and Wang (2000), known as two-stage sintering (TSS), might prove to be a promising approach in obtaining highly dense nano-grained ceramics. TSS has been successfully applied to $\mathrm{ZnO}$ (Mazaheri et al., 2008), $\mathrm{Ni}-\mathrm{Cu}-\mathrm{Zn}$ ferrite (Wang et al., 2006), $\mathrm{BaTiO}_{3}$ (Wang et al., 2006) and $\mathrm{Al}_{2} \mathrm{O}_{3}$ (Bodisova and Sajgalik, 2007). The TSS cycle comprises two main stages (Chen and Wang, 2000), which are heating during the first step, sintering to a temperature (T1) to achieve critical density and lowering the temperature to T2 in order to increase densification without grain growth. As such, it was the objective of the present work to investigate the effects of TSS on the properties of Y-TZP ceramics.

\section{MATERIALS AND METHODS}

\section{Sample Preparation}

The as-received sample of $3 \mathrm{~mol} \%$ yttria stabilised zirconia powder supplied by Kyoritsu, Japan had a total impurity concentration of about 0.1 wt\% with $\mathrm{SiO}_{2}, \mathrm{Fe}_{2} \mathrm{O}_{3}$, $\mathrm{TiO}_{2}$ and $\mathrm{Al}_{2} \mathrm{O}_{3}$ as the major impurities. The Y-TZP powder has a specific surface area of $12 \mathrm{~m}^{2} / \mathrm{g}$ and a mean particle diameter of $300 \mathrm{~nm}$. A total of eight discs $(20 \mathrm{~mm}$ in diameter and $2.5 \mathrm{~g}$ in weight) and four rectangular bars (4 mm x $13 \mathrm{~mm} \times 32 \mathrm{~mm}$ and 3 
g) were compacted uniaxially at $300 \mathrm{kPa}$ and cold isostatically pressed at $200 \mathrm{MPa}$. Consolidation of the particles by pressureless sintering was performed in air using a rapid heating furnace (Modutemp, Australia). The samples were then subjected to four different sintering profiles as shown in Figure 1. All sintered samples were ground on one face using $\mathrm{SiC}$ papers of 120, 240, 600, 800 and 1000 (fine) grades successively, followed by polishing with $6 \mu \mathrm{m}$ and $1 \mu \mathrm{m}$ diamond paste to produce an optically reflective surface.

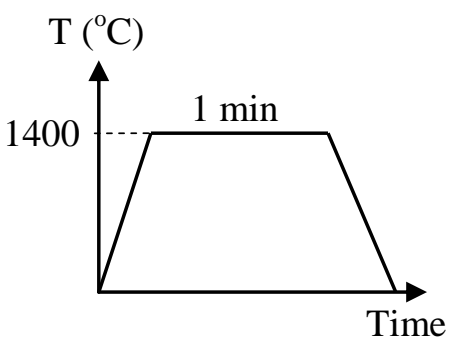

SSS profile 1 (Sample 1)

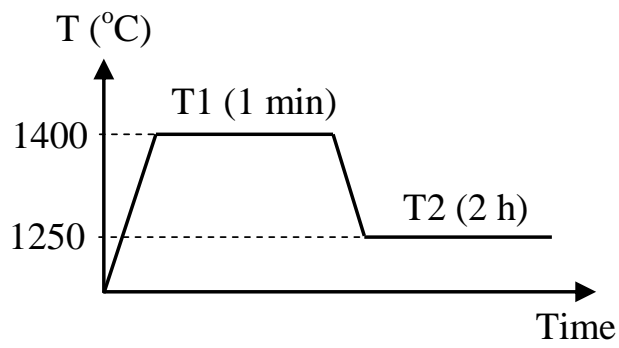

TSS profile 3 (Sample 3)

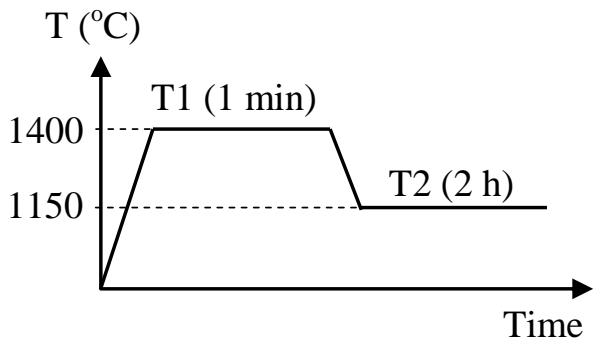

TSS profile 2 (Sample 2)

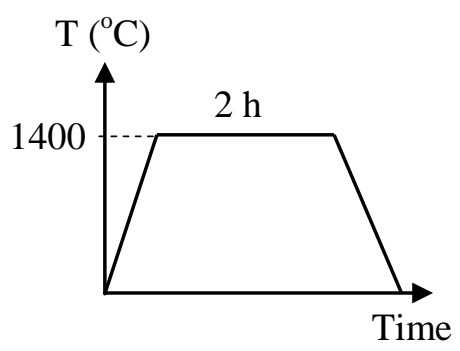

SSS profile 4 (Sample 4)

Figure 1. The various sintering profiles employed in this work.

\section{Characterisation}

The bulk density of the sintered samples was measured based on Archimedes' principle using an electronic balance retrofitted with a density determination kit (Mettler Toledo, Switzerland). The Young's modulus was determined by sonic resonance for the rectangular samples using a commercial testing instrument (GrindoSonic: MK5 "Industrial", Belgium). The instrument permits the determination of the resonant frequency of a sample by monitoring and evaluating the vibration harmonics of the sample by a transducer; the vibrations are physically induced in the sample by tapping. The modulus of elasticity or Young's modulus was calculated using the experimentally determined resonant frequency (ASTM E1876-97, 1998) and the values were found to be consistent regardless of the number of tests performed on each sample. Fracture toughness $\left(\mathrm{K}_{1 \mathrm{c}}\right)$ and Vickers hardness measurements (Future Tech., Japan) were made on polished samples using the Vickers indentation method. The indentation load was kept constant at $100 \mathrm{~N}$ and a loading time of $10 \mathrm{~s}$ was employed. The values of $\mathrm{K}_{1 \mathrm{c}}$ were computed using the equation defined by Niihara et al. (1982). For each test, five measurements were made and the errors were found to be less than 1\%; as such, average values were used for the analysis. 
Phase analysis by X-ray diffraction (XRD: Geiger-Flex, Rigaku, Japan) of the powders and solid samples was carried out under ambient conditions using $\mathrm{CuK} \alpha$ as the radiation source operating at $35 \mathrm{kV}$ in step mode with a $0.02^{\circ} 2 \theta$ step and a count time of $0.5 \mathrm{~s}$ per step over the $2 \theta$ range $27-36^{\circ}$ with a scan speed of $1 \% \mathrm{~min}$; this covers the monoclinic $(\mathrm{m})$ and tetragonal/cubic $(\mathrm{t}, \mathrm{c})$ related $\left\{\begin{array}{lll}1 & 1 & 1\end{array}\right\}$ peaks. The fraction of the monoclinic $(\mathrm{m})$ phase present in the ceramic matrix was determined using the method of Toraya et al. (1984). The hydrothermal ageing experiment was performed in an autoclave containing superheated steam $\left(180^{\circ} \mathrm{C} / 10\right.$ bars $)$ for selected time intervals of 1 , $3,6,9,12,24$ and $50 \mathrm{~h}$. The extent of surface monoclinic development was evaluated by XRD analysis.

\section{RESULTS AND DISCUSSION}

\section{Bulk Density}

The bulk density of the sintered Y-TZP is shown in Figure 2. The results show that sample 4 had the highest relative density of $99.9 \%$, while sample 1 had the lowest relative density of $96.8 \%$. The densities were found to increase as the samples were exposed to longer holding time and at higher sintering temperatures (T2). This correlates well with the observation by Chen and Lu (1989) who found that the sintering temperature is a prime factor affecting the final density of the ceramic. The densification rate was remarkably reduced at the final sintering stage due to coarsening of the microstructure. This is supported by the findings of other researchers (Mazaheri et al., 2008; Bodisova and Sajgalik, 2007; Ghosh et al., 2007; Rahaman, 1991) who have stated that, above a certain critical density, the collapse of open dispersed pores to form closed and small pores accelerates grain growth simply because open pores are not available to pin grain boundary migration through a mechanism known as the solid solution drag mechanism. As such, grain size would increase due to a higher degree of grain boundary migration as compared to grain diffusion.

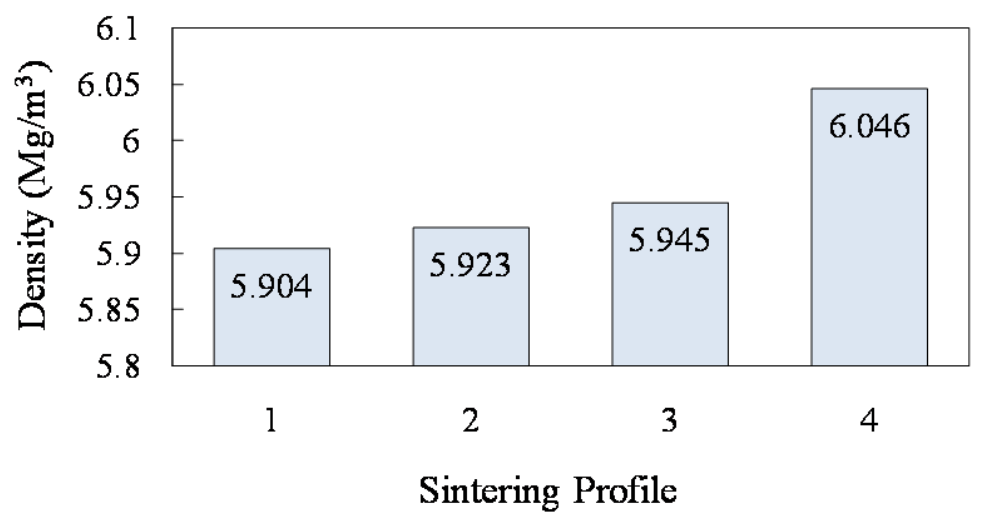

Figure 2. Effects of different sintering profiles on the density of Y-TZP. The sintering profiles are as shown in Figure 1.

Samples 2 and 3 also showed a higher relative density when compared to sample 1 for the same dwell time of 1 minute, thus further reinforcing the advantage of TSS towards densification as compared to SSS. This finding is in agreement with that reported by Chen and Lu (1989). The reduced densification in the sintering of sample 2 
(5.923 Mg/m $\left.\mathrm{m}^{3}\right)$ as compared to sample $3\left(5.945 \mathrm{Mg} / \mathrm{m}^{3}\right)$ could be due to grain coarsening. Insoluble gas entrapped in closed pores may have also retarded the densification process, as described by Rahaman (2003).

\section{Young's Modulus}

Young's modulus, E, was calculated by the flexural resonance frequency technique using rectangular bars; the results are presented in Figure 3. It was found that the Young's moduli for sample 2 (194.6 GPa) and sample 3 (201 GPa) sintered using TSS profiles were higher than sample $1(189.2 \mathrm{GPa})$ following the single-stage sintering profile. Sample 3 exhibited the highest E value, which corresponded to the increase in bulk density. This difference in Young's modulus was attributed to the higher sintering temperature of sample $3\left(1250^{\circ} \mathrm{C}\right)$ as compared to that of sample $1\left(1150^{\circ} \mathrm{C}\right)$. Therefore, sintering at a higher T2temperature seemed to have promoted gain boundary diffusion and inhibited grain boundary migration, thus promoting densification. These results are in complete agreement with the findings of Li et al. (2003).

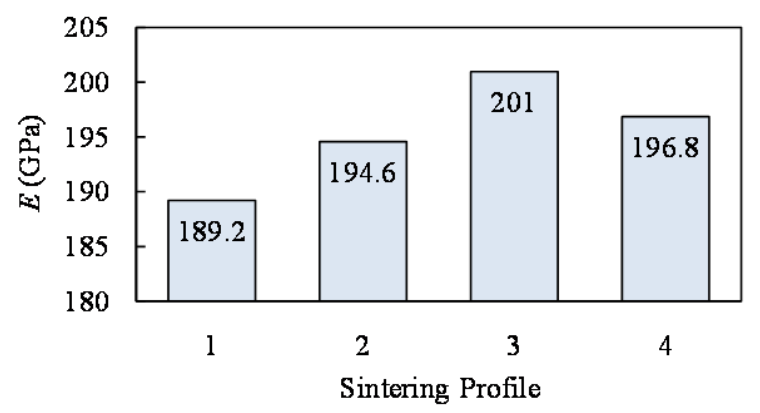

Figure 3. Effect of different sintering profiles on the Young's Modulus of Y-TZP. For sintering profiles, refer to Figure 1.

\section{Fracture Toughness and Vickers Hardness}

The assessments of fracture toughness $\left(\mathrm{K}_{\mathrm{Ic}}\right)$ and hardness were performed on polished samples using the Vickers indentation method. From Figure 4, it can be seen that all samples yielded toughness in the range of 7 to $7.4 \mathrm{MPam}^{1 / 2}$. These findings indicate that the fracture toughness was not affected by the sintering profiles. In terms of hardness (Figure 5), there seemed to be a significant improvement, i.e. from $12 \mathrm{GPa}$ to above 13 GPa. Sample 4 exhibited the highest hardness value of $13.8 \mathrm{GPa}$ which could be attributed an enhancement in densification as depicted in Figure 2.

\section{Hydrothermal Degradation}

To evaluate the resistance of phase transformation between the tetragonal to monoclinic phases, a $50 \mathrm{~h}$ ageing experiment was conducted with intervals of 1, 3, 6, 9, 12, 24 and $50 \mathrm{~h}$. All the samples exhibited a fully tetragonal phase prior to exposure to superheated steam. The XRD analysis performed on all samples, except for sample 4, exhibited a $100 \%$ tetragonal phase after $50 \mathrm{~h}$ of exposure (Table 1). Samples 2 and 3, which underwent two-stage sintering, did not suffer from the ageing-induced tetragonal to 
monoclinic phase transformation, thus indicating that TSS was beneficial in terms of producing a sintered body that is resistant to ageing.

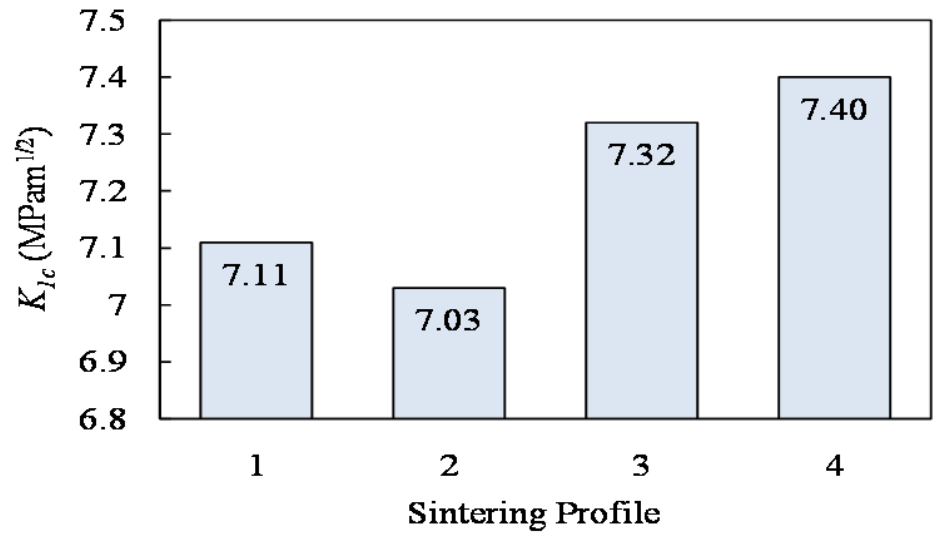

Figure 4. Effects of different sintering profiles on the fracture toughness of Y-TZP ceramics. For sintering profiles, refer to Figure 1.

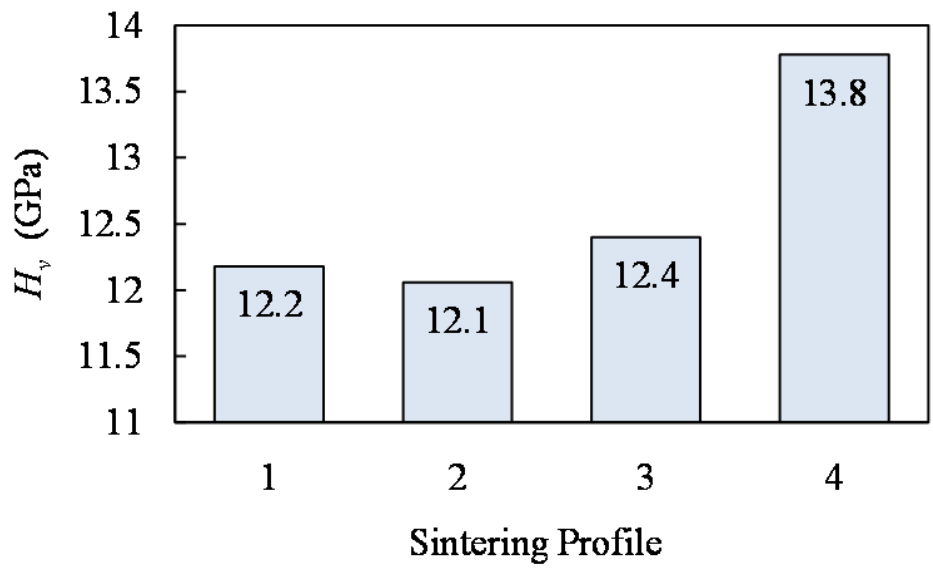

Figure 5. Effect of different sintering profiles on the Vickers hardness of Y-TZP ceramics. For sintering profiles, refer to Figure 1.

Table 1. Effect of hydrothermal ageing on the tetragonal phase content of Y-TZP sintered at different profiles.

\begin{tabular}{ccccccc}
\hline \multirow{2}{*}{ Sample / Profile } & \multicolumn{7}{c}{ Tetragonal Content (\%) } \\
\cline { 2 - 7 } & $\mathbf{1 ~ h}$ & $\mathbf{3 h}$ & $\mathbf{6 h}$ & $\mathbf{1 2} \mathbf{h}$ & $\mathbf{2 4} \mathbf{h}$ & $\mathbf{5 0 ~ h}$ \\
\hline 1 & 100 & 100 & 100 & 100 & 100 & 100 \\
2 & 100 & 100 & 100 & 100 & 100 & 100 \\
3 & 100 & 100 & 100 & 100 & 100 & 100 \\
4 & 55 & 15 & 10 & 9 & 9 & 8 \\
\hline
\end{tabular}


For the single-stage sintering (SSS) profiles, both sample 1 and sample 4 were sintered with the same heating rate up to the same temperature of $1400^{\circ} \mathrm{C}$, but with different holding times, as shown in Figure 1. This is an interesting observation as the results reveal that a 1 min holding time (sample 1) was effective in preventing the ageing-induced phase transformation, as compared to sample 4 which was sintered for 2 h. Sample 1 retained a $100 \%$ tetragonal structure compared to the $8 \%$ tetragonal phase (i.e. $92 \%$ monoclinic phase) found for sample 4 after $50 \mathrm{~h}$ of exposure to superheated steam (Table 1). The development of the monoclinic phase in sample 4 was accelerated after $1 \mathrm{~h}$ of ageing, from zero in the as-sintered condition to about $45 \%$ after $1 \mathrm{~h}$ of exposure. A saturation monoclinic level of about $90 \%$ was attained in this sample after 3 $\mathrm{h}$ of ageing. This was regardless of the fact that sample 4 exhibited the overall best densification and highest mechanical properties. It is envisaged that the 1 min dwell time could have suppressed grain coarsening, resulting in a finer microstructure. An SEM investigation is in progress to elucidate this grain size effect on the ageing properties of zirconia.

\section{CONCLUSIONS}

The present work shows that the sintering profile plays an important role in controlling the physical and mechanical properties of Y-TZP ceramics, particularly when sintering is performed in two stages (TSS) or using a short dwell time. More specifically, a high relative density ( $\sim 98 \%$ of the theoretical value), high hardness $(\sim 12 \mathrm{GPa})$ and a high elastic modulus ( $\sim 200 \mathrm{GPa})$ were measured for Y-TZP ceramics which were heated to $1400^{\circ} \mathrm{C}$ with a dwell time of $1 \mathrm{~min}$ and then subsequently cooled to $1150^{\circ} \mathrm{C}$ at the same ramp rate with a dwell time of 2 hrs. The research also found that Y-TZPs that were heated to $1400^{\circ} \mathrm{C}$ with $1 \mathrm{~min}$ of holding time exhibited comparable properties to those sintered using a 2 hour dwell time. The tetragonal phase stability of these samples was not disrupted by the short dwell time throughout the sintering profile employed. In contrast, the tetragonal stability of sample 4 heated to $1400^{\circ} \mathrm{C}$ and held for $2 \mathrm{~h}$ was completely disrupted within $3 \mathrm{~h}$ of exposure to superheated conditions. This was not the case when a 1 min hold time was employed. The beneficial effect of TSS in promoting densification and suppressing hydrothermal degradation in Y-TZP has been demonstrated.

\section{ACKNOWLEDGMENTS}

The authors would like to thank MOSTI for the financial support under the grant no. 0302-03-SF0175.

\section{REFERENCES}

ASTM E 1876-97. 1998. Standard test method for dynamics Young's Modulus, Shear Modulus and Poisson's Ratio by Impulse Excitation of Vibration. Annual Book of ASTM Standards.

Basu, B., Lee, J. and Kim, D.Y. 2004. Development of nanocrystalline wear-resistant Y-TZP ceramics. Journal of the American Ceramics Society, 87: 1771-1774.

Bodisova, K. and Sajgalik, P. 2007. Two stage sintering of alumina with submicron grain size. Journal of the American Ceramics Society, 90: 330-332. 
Bowen, P. and Carry, C. 2002. From powders to sintered pieces: Formation, transformation and sintering of nanostructured ceramic oxides. Powder Technology, 128: 248-255

Chen, I.W. and Wang, X.H. 2000. Sintering densed nanocrystalline ceramics without final stage grain growth. Nature, 404: 168-171.

Chen, P.L. and Chen, I.W. 1997. Sintering of fine oxide powders. II. Sintering mechanisms. Journal of the American Ceramics Society, 80: 637-645.

Chen, S.Y. and Lu, H.Y.1989. Low temperature aging map for $3 \mathrm{~mol} \% \mathrm{Y}_{2} \mathrm{O}_{3}-\mathrm{ZrO}_{2}$. Journal of Material Science, 24: 453 - 456.

Coble, R.L. and Cannon, R.M. 1978. Processing of crystalline ceramics. Materials Science Research, 11: 151-168.

Cottom, B.A. and Mayo, M.J. 1996. Fracture toughness of nanocrystalline $\mathrm{ZrO}_{2}-3 \mathrm{~mol} \%$ $\mathrm{Y}_{2} \mathrm{O}_{3}$ determined by Vickers indentation. Scripta Materials, 34: 809-814.

Dobedoe, R.S., West, G.D. and Lewis, M.H. 2003. Spark plasma sintering of ceramics. Bulletin of the European Ceramic Society, 1: 19-24.

Garvie, R.C., Hannink, R.H. and Pascoe, R.T. 1975. Ceramic steel? Nature, 258: 703704.

Ghosh, A., Suri, A., Rao, B.T. and Ramamohan T.R. 2007. Low temperature sintering and mechanical property evaluation of nanocrystalline $8 \mathrm{~mol} \%$ yttria fully stabilized zirconia. Journal of the American Ceramics Society, 90: 2015-2023.

Li, J., Tang, Z., Zhang, Z. and Luo, S. 2003. Study of factors influencing the microstructure and phase content of ultrafine Y-TZP. Material Science and Engineering, 99: 321-324.

Masaki, T. 1986. Mechanical properties of toughened $\mathrm{ZrO}_{2}-\mathrm{Y}_{2} \mathrm{O}_{3}$ ceramics. Journal of the American Ceramics Society, 69: 638-640.

Mazaheri, M., Simchi, A. and Golestani-Fard, F. 2008. Densification and grain growth of nano crystalline 3YTZP during two step sintering. Ceramics International, 35: 547-554.

Niihara, K., Morena, H. and Hasselman, D.P.H. 1982. Evaluation of $\mathrm{K}_{\mathrm{Ic}}$ of brittle solids by the indentation method with low crack to indent ratios. Journal of Materials Science Letters 1: 13-16.

Rahaman, M.N. 1991. Sintering technology, sintering and grain growth of ultrafine ceramics powder. New York: Markel Dekker.

Rahaman, M.N. 2003. Ceramic Processing and Sintering, $2^{\text {nd }}$ Edition. New York:. Marcel Dekker.

Ran, S., Winnubst, L., Wiratha, W. and Blank, D.H.A. 2006. Sintering behavior of 0.8 mol\%-CuO-doped 3Y-TZP ceramics. Journal of American Ceramics Society, 89: 151-155.

Toraya, H., Yoshima, M. and Somiya, S. 1984. Quantitative analysis of monoclinic stabilized cubic $\mathrm{ZrO}_{2}$ systems by x-ray diffraction. Journal of the American Ceramics Society 67, C-119.

Tsukuma, K., Kubota, Y. and Tsukidata, T. 1984. Thermal and mechanical properties of $\mathrm{Y}_{2} \mathrm{O}_{3}$-stabilised tetragonal zirconia polycrystals. Science and Technology of Zirconia, The American Ceramics Society, Columbus, 465-479.

Wang, J. and Gao, L. 2005. Photoluminesence properties of nanocrystalline $\mathrm{ZnO}$ ceramics prepared by pressureless sintering and spark plasma sintering. Journal of the American Ceramics Society, 88: 1637-1639. 
Wang, X.H., Deng, X.Y., Bai, H.L., Zhou, H., Qu, W.G. and Li, L.T. 2006. Two step sintering of ceramics with constant grain size, II: $\mathrm{BaTiO}_{3}$ and $\mathrm{Ni}-\mathrm{Cu}-\mathrm{Zn}$ ferrite. Journal of the American Ceramics Society, 90: 438-443.

Weibel, A., Bouchet, R., Denoyel, R. and Knauth, P. 2007. Hot pressing of nanocrystalline $\mathrm{TiO}_{2}$ (anatase) ceramics with controlled microstructure. Journal of the European Ceramic Society, 27: 2641-2646. 